\title{
Perspective
}

\section{Ebola Virus Disease in sub-Saharan Africa: Addressing Gaps to}

\section{Handle Future Outbreaks}

\author{
Elizabeth Armstrong-Mensah ${ }^{1 *}$, Bianca Tenney ${ }^{1} \&$ Victoria Hawley $^{1}$ \\ ${ }^{1}$ Georgia State University, Atlanta, Georgia \\ *Corresponding Author, E-mail: earmstrongmensah@gsu.edu
}

Received: June 29, 2021

Accepted: July 9, 2021

Online Published: July 27, 2021

doi:10.22158/rhs.v6n3p28

URL: http://dx.doi.org/10.22158/rhs.v6n3p28

\begin{abstract}
Between 2014 and 2016, the three West African countries of Guinea, Liberia and Sierra Leone experienced the deadliest Ebola virus disease (EVD) outbreak in sub-Saharan Africa. Two years later, a tenth epidemic recurred in the Democratic Republic of Congo (DRC), specifically in the North Kivu and Ituri provinces, which lasted until June 2020. Though they occurred in different countries, a review of how the EVD outbreaks in Guinea, Liberia, Sierra Leone, and the DRC were handled by the respective country governments, reveal gaps in disease detection, response and action due to lack of surveillance, an EVD preparedness plan, and weak health systems. This perspective discusses the EVD outbreaks in Guinea, Liberia, Sierra Leone, and the DRC, their effects, and draws attention to gaps that need to be addressed by these countries in order to be better prepared to handle future outbreaks. Acting on the proposed recommendations will not only benefit Guinea, Liberia, Sierra Leone, and the DRC in the future, but will be of benefit to EVD susceptible countries in sub-Saharan Africa, as we live in a global community where diseases are no respecters of boundaries.
\end{abstract}

\section{Keywords}

Ebola virus disease, sub-Saharan Africa, surveillance, preparedness plan, health system

\section{Introduction}

Ebola virus disease (EVD), also known as Ebola hemorrhagic fever, is one of the deadliest re-emerging infectious diseases in sub-Saharan Africa (Centers for Disease Control and Prevention, 2021). First emerging in the Democratic Republic of Congo (DRC) in 1976, the disease has broken out in over 20 countries in sub-Saharan Africa including Gabon, the Ivory-Coast, Uganda, Zaire, and Sudan (Bell, Damon, Jernigan, et al., 2016). The most lethal of all outbreaks thus far, are those that occurred between 2014 and 2016 in the three West African countries of Guinea, Liberia, and Sierra Leone 
(Shears \& Garavan, 2020), claiming over 11,300 lives (Bell, Damon, Jernigan, et al., 2016) and the recent outbreak in the DRC in 2018.

While the outbreaks occurred at different points in time, a common thread connecting them is the fact that the impacted countries have weak health systems, a history of civil war and political unrest, and have no surveillance system and EVD plans (Bell, Damon, Jernigan, et al., 2016). This perspective discusses the EVD outbreaks in Guinea, Liberia, Sierra Leone, and the DRC, their effects, and draws attention to gaps that need to be addressed by these countries in order to be better prepared to handle future outbreaks.

\section{Effects of the 2014-16 and 2018-20 EVD Outbreaks}

EVD is an infectious disease transmitted by an unknown animal reservoir to humans or through direct human contact with contaminated body fluids. The 2014-16 and the 2018-20 EVD outbreaks in sub-Saharan Africa had significant effects. They interrupted trade, tourism, mining, agricultural production, education, and the provision of regular health care by health systems (Kaner \& Schaack, 2016). Economically, Guinea, Liberia, and Sierra Leone lost about $\$ 2.2$ billion in gross domestic product (United Nations Development Group, 2015). These countries also experienced more than 21,000 confirmed cases of EVD and over 11,000 fatalities (United Nations Development Group, 2015). The fatalities severely impacted their health workforce - Liberia lost $8 \%$ of its doctors and nurses, Sierra Leone 7\%, and Guinea 1\% (Centers for Disease Control and Prevention, 2019). The provision of health care services in these three countries plummeted by $50 \%$, causing about 10,600 fatalities among human immunodeficiency virus (HIV), tuberculosis, and malaria patients. Educationally, by June 2015, students in these countries had lost a total of about 1,848 hours of education as schools had been closed. School closures ranged from 33 weeks in Guinea to about 39 weeks in Sierra Leone (United Nations Development Group, 2015).

By August 2019, the DRC had experienced over 2,763 EVD infections. About 1,849 of those infected died (Stoop, Desbureaux, Kaota, Lunanga, \& Verpoorten, 2021). The outbreak impacted 26 health zones in the North Kivu and Ituri provinces (Stoop, Desbureaux, Kaota, Lunanga, \& Verpoorten, 2021). Ongoing conflict and the lack of security, displaced over 2 million people internally, making the epidemic one of the most complex ever experienced by the country. Economic growth in the DRC slowed down by 15\% during that period (Stoop, Desbureaux, Kaota, Lunanga, \& Verpoorten, 2021).

\section{Gaps and Future Outbreak Challenges}

A review of how the EVD outbreaks in Guinea, Liberia, Sierra Leone, and the DRC were handled, reveal gaps in disease detection, rapid response and action due to inadequate surveillance and data collection, a lack of EVD preparedness plans, and weak health systems. 


\subsection{Surveillance and Data Collection}

The collection of accurate and timely surveillance data is critical during public health emergencies since it provides information needed to determine staffing and resource needs and how to allocate them (McNamara, Schafer, Nolen, et al., 2016). During the 2014-16 EVD outbreaks, health care workers in Guinea initially misdiagnosed the first cases of EVD as cholera or Lassa fever. This was because the disease was newly emerging in the country (Kaner \& Schaack, 2016). The misdiagnosis contributed to the rapid transmission of the virus from rural areas in Guinea to the neighboring boarder countries of Sierra Leone and Liberia.

Unlike Guinea, the DRC was able to identify the disease after the first few cases were reported in the Mabalako Health Zone of North Kivu. However, increased population movement from EVD hotspots and the lack of adequate surveillance systems hindered rapid response to new cases (McNamara, Schafer, Nolen, et al., 2016). The presence of armed troops, due to the ongoing conflict in the affected areas, coupled with a series of attacks on health workers, made the containment of the outbreak difficult (Shears \& Garavan, 2020), facilitating the transmission of EVD to previously unaffected areas. Although surveillance systems were later set up in Guinea, Liberia, and Sierra Leone during the epidemic by the Centers for Disease Control and Prevention (CDC), there were issues. Communities were reluctant to report cases, and there were few trained outbreak response staff who could collect and analyze surveillance data. There were also problems with the timely collection, compilation, and transmission of surveillance data to where they were needed (McNamara, Schafer, Nolen, et al., 2016). Additionally, there were challenges with EVD case definitions; while Guinea and Liberia used the CDC and World Health Organization (WHO) definitions, Sierra Leone used a narrower definition. Even after case definitions in these countries were aligned, there were difficulties with ensuring individual nationwide application at all levels (McNamara, Schafer, Nolen, et al., 2016).

To be better prepared to adequately detect and rapidly respond to future EVD outbreaks, the governments of Guinea, Liberia, Sierra Leone, and the DRC and other at risk sub-Saharan African countries need to be educated on the importance of not only collecting accurate surveillance data, but also on the need to train health care workers to analyze collected data and to rapidly disseminate them so necessary actions can be taken (McNamara, Schafer, Nolen, et al., 2016). Awareness also needs to be created at the community level to encourage people to report cases to the appropriate entity. Additionally, the governments need to commit to ensuring that consistent EVD case definitions are in place across the board and that their health care workers at the local and national levels are adequately trained in how to implement them in the future.

\subsection{EVD Preparedness Plan}

Putting in place an effective EVD outbreak preparedness plan for the timely containment of outbreaks is critical (Bell, Damon, Jernigan, et al., 2016). During the 2014-2016 and 2018-20 EVD outbreaks, it was evident that the countries impacted had no such plan in place. After the outbreaks, using an assessment tool comprising various checklist domains, the WHO worked with partner countries to 
assess their EVD preparedness (World Health Organization, 2015). At present, all WHO regions have intensified EVD preparedness activities and at-risk countries are striving to ensure operational readiness to detect, investigate and report future EVD cases and to mount an effective response in the short term effectively and safely (United Nations Development Group, 2015). However, while a step in the right direction, these plans are short-term and dependent on partner support. To be effective, previously impacted and at risk countries in sub-Saharan Africa need to fast-track and produce longer term plans that focus on mobilizing local resources to fund preparedness strategies (World Health Organization, 2015).

\subsection{Health Systems}

Sierra Leone, Liberia, and the DRC are among countries in sub-Saharan Africa with the lowest investments in health care infrastructure. With under resourced and understaffed hospitals and health centers, these countries were unable to halt the EVD outbreak (Nyenswah, Kateh, Bawo, et al., 2016). Per an assessment conducted by the CDC in 2014 in Sierra Leone, most health professionals in Port Loko lacked formal training in EVD prevention and infection control. Additionally, personal protective equipment in health facilities in Sierra Leone were insufficient and the number of health professionals across all levels of the health system was inadequate (Pathmanathan, O'Connor, Adams, et al., 2014). According to the Liberia Ministry of Health and Social Welfare (MOHSW), several healthcare facilities (nearly 57\%) lacked protocols for triage and isolation of persons suspected to have EVD, 43\% lacked access to gloves, face shields, or gowns, and 24\% lacked running water (Nyenswah, Kateh, Bawo, et al., 2016). Regarding the DRC, the United Nations Children's Fund (UNICEF) indicated that the country's healthcare system was "on life support" lacking medical supplies, equipment, and funds, and almost $50 \%$ of the nation's health facilities lacked basics such as clean water and sanitation facilities (Gigova, 2020).

Strengthened health systems require evidence-based policy reforms and adequate health planning and financing. They also require sufficient capacity across all preparedness and response pillars at subnational, particularly district-levels, as well as adequate infection prevention and control practices and a well-trained health workforce. Thus, the governments of previously impacted and at risk EVD countries need to rethink their budgetary allocations to their health systems. They need to ensure that they have enough supplies and protective equipment, as well as trained health care workers that can respond at any time, should an outbreak occur. While the international community provides assistance during an outbreak, EVD countries need to learn from past experiences and be ready to tackle future outbreaks on their own prior to the arrival of international assistance.

\section{Conclusion}

The Ebola epidemics in Guinea, Liberia, and Sierra Leone were profound tragedies. Indeed, they put global health security on the global agenda. While important lessons have been learned in the aftermath of the crises, intentional efforts must be made by governments so as to prevent or significantly decrease 
country vulnerability to future outbreaks. Reliable and consistent surveillance systems need to be developed, national preparedness plans with long and short-term goals need to be established, and appropriate health care personnel need to be trained at ready to take on any outbreak should one occur.

\section{References}

Bell, B. P., Damon, I. K., Jernigan, D. B., et al. (2016). Overview, Control Strategies, and Lessons Learned in the CDC Response to the 2014-2016 Ebola Epidemic. MMWR Suppl., 65(3), 4-11. http://doi.org/10.15585/mmwr.su6503a2 PMID: 27389903

Centers for Disease Control and Prevention. (2019). Cost of the Ebola Epidemic [Internet]. Atlanta: Centers for Disease Control and Prevention; 2019. Retrieved February 19, 2021, from https://www.cdc.gov/vhf/ebola/history/2014-2016-outbreak/cost-of-ebola.html\#N4

Centers for Disease Control and Prevention. (2021). History of Ebola Virus Disease [internet]. Atlanta: Centers for Disease Control and Prevention; 2021. Retrieved April 29, 2021 from https://www.cdc.gov/vhf/ebola/history/summaries.html

Gigova, R. (2020). DRC's health system is 'on life support' as it fights several killer diseases, including coronavirus [internet]. Atlanta: CNN; 2020. Retrieved May 26, 2021, from https://www.cnn.com/2020/04/22/africa/drc-coronavirus-killer-diseases-intl/index.html

Kaner, J., \& Schaack, S. (2016). Understanding Ebola: the 2014 epidemic. Global Health, 12(1), 53. http://doi.org/10.1186/s12992-016-0194-4 PMID: 27624088

McNamara, L. A., Schafer, I. J., Nolen, L. D., et al. (2016). Ebola Surveillance - Guinea, Liberia, and Sierra Leone. MMWR Suppl., 65(3), 35-43. http://doi.org/10.15585/mmwr.su6503a6

Nyenswah, T. G., Kateh, F., Bawo, L., et al. (2016). Ebola and Its Control in Liberia, 2014-2015. Emerg Infect Dis., 22(2), 169-177. http://doi.org/10.3201/eid2202.151456 PMID: 26811980

Pathmanathan, I., O’Connor, K. A., Adams, M. L., et al. (2014). Rapid assessment of Ebola infection prevention and control needs--six districts, Sierra Leone, October 2014. MMWR Morb Mortal Wkly Rep., 63(49), 1172-1174. https://www.cdc.gov/mmwr/preview/mmwrhtml/mm6349a7.htm PMID: 25503922

Shears, P., \& Garavan, C. (2020). The 2018/19 Ebola epidemic the Democratic Republic of the Congo (DRC): epidemiology, outbreak control, and conflict. Infect Prev Pract., 2(1), 100038. http://doi.org/10.1016/j.infpip.2020.100038

Stoop, N., Desbureaux, S., Kaota, A., Lunanga, E., \& Verpoorten, M. (2021). Covid-19 vs. Ebola: Impact on households and small businesses in North Kivu, Democratic Republic of Congo. Elsevier World Dev., 140, 105352. http://doi.org/10.1016/j.worlddev.2020.105352

United Nations Development Group. (2015). Socio-Economic Impact of Ebola Virus Disease in West African Countries: A call for national and regional containment, recovery and prevention. New York: United Nations Development Group - Western and Central Africa; 2015. Retrieved February 19, 2021, from https://www.undp.org/content/dam/rba/docs/Reports/ebola-west-africa.pdf 
World Health Organization. (2015). Ebola virus disease preparedness: taking stock and moving forward, report of a WHO meeting. Geneva: World Health Organization; 2015. Retrieved May 26, 2021, from https://apps.who.int/iris/handle/10665/152132 